\title{
Women's education and entry into a first union. A simultaneous-hazard comparative analysis of Central and Eastern Europe
}

\author{
Francesco C. Billari and Dimiter Philipov
}

\begin{abstract}
The impact of education on women's union formation has long been studied in empirical analyses based on economic and sociological theories. In particular, the literature has shown that the transition to a first union is triggered by the end of education. Mixed evidence has been found on the impact of the level of education. On the other hand, entry into a union usually triggers the end of education. However, the potential endogeneity of educational enrolment and of the timing of union formation has rarely been assessed. In this paper, we use a simultaneous-hazard two-equation model to assess the mutual impact of careers and their potentially common (unobserved) determinants. More specifically, we focus on a yet unstudied institutional setting, namely Central and Eastern European countries. We use micro-data from Fertility and Family Surveys, which refer mainly to the pre-transition period but allow to shed a first light on changes occurring during the transition. Our results for women show that educational enrolment has a key impact on first union formation, but that also the level of education has a substantive impact as expected by Becker's theory. On the other hand, union formation in almost all countries triggers the end of education. Common unobserved determinants of the two careers have a relatively weak importance.
\end{abstract}

\section{Introduction}

The impact of education on women's union formation has for a long time been studied making use of economic and sociological theories of marriage-see above all Becker (1991) and Oppenheimer (1988) ${ }^{1}$. Empirical studies that use micro-level event-history data have repeatedly shown that finishing formal education triggers union formation. On the other hand, mixed evidence has been found on the impact of educational attainment on union formation. For instance, in an earlier paper Hoem (1986) showed that educational enrolment was more important than educational level for Sweden. In an influential paper, Blossfeld and Huinink (1991) showedwithin a sociological theoretical framework-that the same result was true for Ger-

1 A recent review of the literature can be found in Coppola (2003), Chapter I. 
many; more specifically, in the study of Blossfeld and Huinink the impact of educational level on the transition rate to first union was not statistically significant, when educational enrolment was controlled for.

The inherent problem of endogeneity has however been addressed much less frequently. We refer to the fact that part of the impact of education on union formation can be due to spurious dependence (on common factors that we shall discuss later); procedures estimating the impact of educational attainment and enrolment on the timing of first union that do not take this into account can lead to biased results. Surprisingly, given the idea that it may be necessary to "account for tastes" as well, endogeneity has long been of relatively limited interest among demographers and sociologists; economists and economic demographers, on the contrary, have seriously been concerned about this issue. In an earlier paper, within the New Home Economic framework, Boulier and Rosenzweig (1984) explicitly discussed the potential endogenous determinants of schooling and marriage, and they showed that endogeneity due to common unobserved determinants was present using data from the Philippines. In particular, Boulier and Rosenzweig argued that human capital investments are partially guided by a woman's marriage market potential. Lillard et al. (1994) also deal with the potential endogeneity of fertility, marital and educational experiences (see also Upchurch et al., 2001). Sander (1992) illustrates the endogeneity of educational status when studying marital status. In addition, several studies have shown that forming a family while being enrolled in education raises the risks of terminating education or of attaining generally lower educational levels (in particular, see Alexander and Reilly, 1981; Astone and Upchurch, 1994; Henz, 1999).

It is useful, in our view, to assume that educational career and the formation of a first union are interrelated processes in the life course. We thus see them as characterised by 1) mutual influence - that is events in one process trigger events in the other process-and 2) common time-constant influencing factors-which are usually not observed especially in retrospective surveys and which represent sources of potential endogeneity. If we adopt this point of view, it is of crucial importance both to assess the presence of endogeneity and to hypothesise about its possible origins. The importance of subjective dimensions (value orientations, norms, and attitudes) may lie at the heart of it, but as discussed in the economics literature, also personal attractiveness and ability may play a role.

Almost all papers dealing with the relationships between education and union formation so far have dealt with either Western countries or less developed countries. The literature has hitherto ignored Central and Eastern European (CEE) countries. These countries formerly constituted the Communist block, and they exhibited a surprising stability in aggregate-level behaviour, with very low monetary returns to education and with remarkably high labour force participation of women. The need to test general theories can make use of the specific peculiarities of CEE countries, also because of the changes (mostly in returns to education) that have been triggered by the transition. 
We conduct a comparative event-history analysis on seven CEE countries using data from the Fertility and Family Surveys (FFS) that were carried out during the Nineties. We apply simultaneous hazard equations with correlated unobserved heterogeneity, as outlined e. g. by Lillard (1993). Our results indicate consistently for all countries that educational enrolment is in general more important than the current level of education for the timing of first union. On the other hand, entering a union raises the probability of terminating education. The importance and nature of common unobserved determinants differs among countries. The paper is structured as follows. In Section 2, we outline the background of the study, focusing on theoretical ideas as well as on existing results of the relationships between educational enrolment and attainment and union formation. In Section 3, we discuss the specific situation of Central and Eastern Europe. Section 4 introduces the data we use as well as our methods of analysis. Results are presented and discussed in Section 5. Section 6 summarises and concludes the paper.

\section{Background}

In this Section, we discuss the impact of the educational career on the timing of first union formation and vice-versa, emphasising on our way possible sources of endogeneity, which may cause spurious dependence when estimating mutual impacts.

\subsection{Educational career and first union formation}

A classical theoretical approach is based on New Home Economics, as pioneered by Becker (1991, and earlier citations therein) ${ }^{2}$. Becker hypothesises that women who have attained higher educational levels are potentially more independent from men from a financial point of view, in societies where a traditional division of labour prevails in the household. With the increase in women's educational attainment, and increase in the accumulation of human capital, the gains from marriage become less significant. Highly educated women are less affected by the economic advantages of marriage, and they are more likely to postpone marriage than women with lower educational levels. In addition, the opportunity costs of time spent for the family increase with human capital, independently of whether the family is formed through a marriage or a non-marital union.

In terms of empirical focus, the new home economics approach emphasises educational attainment over educational enrolment. An alternative approach emphasises the importance of educational enrolment, i.e., time spent as a student. Hoem (1986) finds that in Sweden the length of education is more important for the entry into first union than the level of education. Goldscheider and Waite (1986) show that educa-

2 See also the review by Weiss (1997). 
tional enrolment matters more for women than for men. Blossfeld and Huinink (1991) find the same results in a broader framework. They justify this finding with the presence of sequencing life-course norms (Hogan, 1978; Marini, 1984). Blossfeld and Huinink suggest that "...participation in the education system takes time and affects women's ability to marry... When a woman is attending school, university ... she is economically highly dependent on her parents. Further, there exist normative expectations in society that young people who attend school are "not at risk' of entering marriage...". Therefore, educational enrolment is not just a crude proxy for the period of human capital accumulation. Being in education per se has a direct effect on the life course, and in particular on family formation, in so far as during the period of study people center time and efforts on studying and not on starting family life. Further theoretical arguments, together with empirical analyses of the impact of educational enrolment on young adults' union formation are presented by Thornton et al. (1995), who show that human capital accumulation matters also for the choice of marital versus non-marital first union, and by Liefbroer and Corijn (1999).

Oppenheimer (1987) focuses on the relationship between timing of marriage and starting first stable occupation. She discusses assortative mating in the light of the job-search theory. The higher the uncertainty in the matching process, the more inclined is a person to postpone marriage, until substantive life course events contribute to a decrease in the uncertainty of the future relationship. During a period of educational enrolment uncertainty is large because it is unclear how the individual's human capital will rank on the labour market. Uncertainty in a person's possibilities on the labour market decreases once his/her educational enrolment is completed. A person with a higher educational level is preferred over others with lower levels and therefore is expected to end his/her personal search mating process faster. Although Oppenheimer's theory has been mostly used to explain men's behaviour, her ideas are also useful when focusing on women. Interestingly, other authors have argued that marriage itself can be a strategy used to reduce uncertainty in people's lives, especially when other "uncertainty-reduction" choices are not available (Friedman et al., 1994).

To sum up, approaches à la Becker or Oppenheimer underline the significance of the level of education, for its economic or signaling potential, as a determinant of the timing of entry into first unions. The sequencing-norm approach theorised by Blossfeld and Huinink gives more importance to educational enrolment than to the level of education: the longer the education, the more delayed the union.

Lesthaeghe and Moors (1995) provide a different perspective in their study of the living arrangements. Their approach, based on the idea of a "Second Demographic Transition" (see van de Kaa, 1987) emphasises the significance of value orientations in shaping people's lives. Persons with more "modern" value orientations are more likely to postpone marriage and to prefer non-marital unions to marriage. So are persons with higher levels of education, since their value systems are more modern. In general, we may use the perspective based on value orientations by thinking that part 
of the observed impact of educational enrolment in postponing union formation is due to dependence from unobserved value orientations, part of which is constant. Hakim's "Preference Theory" actually postulates that women can be divided in three groups that are grosso modo derived from a continuum from full career orientation to full family orientation (see e. g., Hakim, 2003). Janssen and Kalmijn (2002) show that individuals who are career-oriented tend to postpone union formation as well, while family-oriented individuals opt for educational careers that are deemed compatible with family life. Value orientations change significantly after the experience of life-course events (for instance the first union) and for this purpose we shall focus on first union only. Past estimates of the impact of educational enrolment may be biased for the dependence on unobserved and heterogeneously distributed factors such as value orientations. The same spurious dependence may be observed if the propensity to obey to the sequencing norm outlined by Blossfeld and Huinink varies within a population.

\subsection{Union formation during educational enrolment and its impact}

The theoretical considerations briefly discussed above are not used to explain the inverse relationship, namely that of the effect of entry into a union on the level or length of education. Oppenheimer (1988, p. 583) notes that "... 'premature' commitment to a marriage may require just such dropout [from college] behavior". The existence of this relationship within the realm of each theoretical approach can rest, for example, on the following consideration. Under conditions of traditional division of labour in the family, a woman is expected to end her education after a marriage because she needs to take up the household work. Where an equal distribution of household labour prevails, both partners will face high opportunity costs for the time spent on household chores. It could then be more effective for the household production unit to revert to the traditional labour division. Therefore, a longer education or higher-level education induces postponement of entry into first union and, inversely, early entry into union triggers an earlier end of educational enrolment. This mutual relationship is due to the conflicting roles of full-time student and family career (especially for women). This conflict is placed in the complex social and economic environment of uncertain expectations about future occupational and family career. Both processes are linked at the macro level too, in that the highest proportions of educational enrolment and entry into first union are observed at very close ages.

It can be argued that there are other reasons for the existence of mutual relationships. For example, consider a case where a person is experiencing difficulties while studying at a high educational level. His/her abilities could be insufficient for this particular level. In this case, for an individual it is rational to search for a change in the life course based on an expected dropout of school (university), for instance as a strategy for uncertainty reduction in the sense of Friedman et al. (1994). Inversely, the better one is doing with the process of study the more likely the studies will be 
continued to higher levels, and therefore entry into union is more likely to be postponed. Thus, personal ability as a student can be a reason for the interrelationship between timing of end of education and entry into first union.

The latter example illustrates the necessity to consider personal characteristics that may have a significant impact on the decision to sequence the two events of interest here. Oppenheimer (1988, p. 565) notes “... the high degree of uncertainty about the important attributes that people attempt to match". Uncertainty in the decision-making process of rational actors plays a key role in her theoretical framework. The same is true for the new home economics approach, the latter being based on utility theory.

Beside uncertainty, we face the problem of unobserved and even unobservable individual characteristics. In our example above the two processes were considered linked through "ability". It is unlikely to expect observations of ability in retrospective demographic surveys, before the end of education (the level of education could be a proxy for ability but in our context this proxy is of course of no use). Therefore, we have to consider this as part of unobserved individual heterogeneity.

A substantial part of the literature on the impact of family formation on educational careers has been concentrated on adolescent pregnancies and on their impact on schooling. For instance, Upchurch and McCarthy (1990) found no effect of first births on the timing of high school dropout and of high school completion, without accounting for the potential endogeneity problem. Their study, as well as some of the following studies, have focused mostly on adolescent pregnancy, however. The endogeneity issue is thoroughly addressed in other papers aiming more explicitly at grasping causal links on the consequences of teenage childbearing (see e. g., Hotz et al., 1997).

As far as the specific impact of union formation on educational careers is concerned, seminal studies are the ones by Davis and Bumpass (1976), and Alexander and Reilly (1981) on the consequences of early marriage on educational attainment. These studies convincingly show that early marriage induces dropping out of school. This impact is stronger for women than it is for men. Later studies like the one of Astone and Upchurch (1994) have found that women who form a family while still being enrolled in high school have an higher risk of leaving school without earning a degree. Lillard et al. (1994, see also Upchurch et al., 2001) studied simultaneously, among other events, the impact of union formation on educational careers (not limiting themselves to high school completion) and the impact of educational careers on union formation. They find that "women who became pregnant in their 'current' schooling decision window were much less likely to go on to the next grade level" ( $\mathrm{p}$. 42 ), and the same finding holds true at college level as well. Another stream of research deals with the disruptive impact of marriage on young women's education in less developed countries (Singh and Samara, 1996). 


\section{The peculiarities of Central and Eastern European countries}

The general theoretical considerations and the existing literature that we reviewed in the previous section refer to societies with functioning market economies or, to a limited extent, to less developed countries. The usefulness of the different theoretical perspectives for a context like that of CEE countries (before and after the transition) has never been considered, and only few studies have discussed empirical relationships. Indeed, these countries had planned economies till 1989, and the 1990s witnessed a transition towards a market economy. Labour markets and the educational systems in these countries were different-in many aspects-from the ones in the Western societies.

Consider first the situation before the start of the societal transition. During the socialist regime, education at any level was free and therefore, at least in principle, accessible to everyone. However, unequal access to higher education was also common (Barrow, 1998). Higher education was planned, in that the number of students was fixed by the state planning organs. This number was rapidly increasing over time, as a part of the overall tendency to boost education. The gender distribution of the students was also planned around 50\% for each group. Unemployment was considered to be non-existent. Even frictional unemployment was disregarded. Young people were thus able to start their working "career" immediately or soon after the completion of education. Payment of labour was uniform for diverse categories of labour, although the level of education was an important indicator for the level of payment. Given the lack of possibilities for market initiatives, higher education was however an important prerequisite to get higher standards of living even in pre-transition CEE. The mean age at first marriage for women was below 23 years all over the region and did not change for decades (Hajnal, 1965; see also Philipov and Dorbritz (2003) for a detailed descriptive study of demographic changes in the CEE countries). In general, people started their family lives at an early age. Various explanations have been invoked for this early start, and one of them is that uncertainty in the future life was low. The totalitarian regime did not tolerate deviant behaviour and thus contributed to the preservation of norms, for example those related to life cycle events. Traditional division of labour in the family gave way only very slowly to the uniform distribution.

During the transition period the situation changed considerably (for various views on these changes see Kotowska and Jóźwiak, 2003). Although at varying paces, the labour market widened and developed quickly. Unemployment rose to unprecedented levels. Paid education emerged and planned education collapsed. New universities and other high schools came into being. Uniformity in the payment of labour disappeared, both impoverishment and enrichment rose. Entry into marriage was postponed to later years in life, and marriage gave way to non-marital unions. All these changes are represented by tendencies whose development is at present still continuing. It is clear today that the transition process is taking longer than previously expected, especially in some countries. Sowa (1999) discusses the transition in 
the educational system and indicates that it needs more time than the economy itself, although for many countries the accession to the European Union will inevitably imply a quicker convergence to the West for instance where educational institutions are concerned. Lesthaeghe and Surkyn (2002) have shown, using the European Values Surveys of 1999, that the "tolerance" for new forms of household formation is increasing. For our purposes, we may expect this to be an indicator that after the economic transition individual-level differences in orientations will play a more important role than in the past.

Let us now consider the above description from the point of view of the literature discussed in Section 2, focusing on the socialist period and the changes we may expect.

The right to work and the access to higher educational level contributed to an increase in female autonomy as well as to rising opportunity costs of time spent for family occupations (although child-care provision varied across CEE countries). Hence, according to the new home economics approach, first union formation of highly educated women should be (at least) postponed also in a socialist setting. At the macro-level, one would expect that the rising share of people achieving higher education would imply a postponement in the mean age at first marriage, or first entry into a union. Macro-level demographic data, however, do not support the existence of such trends. The transition to a market economy, with a rise in opportunity cost for family life, may accentuate the importance of educational attainment for the timing of first union formation.

Young adults living in a socialist state before 1989 had less uncertainty in the future life course, compared to their peers living in the West. For example, the process of search in the labour market was "eased" by the lack of unemployment and the uniformity in labour earnings. Therefore, an individual could construct plausible expectations for an approximate level of earnings and for work in general. Hence the theory of marriage timing suggested by Oppenheimer becomes less relevant because of the lower uncertainty. If asymmetric causality holds, lower level of uncertainty would imply earlier entry into marriage and perhaps inversion of life events, such as the completion of education and entry into a union. It remains unclear though whether this logical inversion of the theoretical framework is itself theoretically justifiable.

Let us now consider the impact of educational enrolment. The preservation of traditional social norms on role separations during the socialist decades leads us to expect that educational enrolment indeed contributes to postponing the formation of a first union. If such norms break during the transition, it is difficult to forecast the direction of change in terms of impact after the transition.

Finally, let us consider the impact of ability on education. As stated above, its measurement by the level of achieved education is too crude and anyway not useful in our context. In CEE countries this measurement is even cruder. In general, costs of education were low, for example due to stipends and various social benefits guaranteed to students. The attractiveness of education therefore stimulated people to take 
the chance to complete a higher level without incurring great costs. Therefore, even on persons with a relatively lower ability in studies, there was only a moderate economic pressure, if any, to drop out of education. However, the idea that sequencing norms pervaded also the socialist era leads us to expect that starting a union triggers the end of education.

In general, the theoretical approaches considered above seem applicable when referring to CEE countries before the transition and shortly after its start, although not as explicitly as in countries with lasting market economies.

\section{Data and methods}

\subsection{Data: Fertility and Family Surveys}

We use data from the series of Fertility and Family Surveys (FFS) that was carried out mainly in the Nineties with the co-operation of the Population Activities Unit of the Economic Commission for Europe of the United Nations. In particular, we use the data of the so-called "standard recode files" that were available to us at the time of preparation of this paper, and we focus on countries in Central and Eastern Europe (CEE). The surveys asked for timing of life course events, and they allow building event histories for education and union. We use data for Poland, Hungary, the Czech Republic, Lithuania, Latvia, Estonia, and Slovenia. In Table 1 we report the timing of FFS surveys in the countries we analyse. In Table 2 we report some descriptive statistics on the mean age at the end of education, at the completion of relevant educational levels, and at first union, together with the share of women with level 3 education. Three levels of education are considered, namely unfinished secondary, secondary, and higher than secondary. By secondary education we mean the one that requires some 10-12 years in school. The reliability of the age at which women leave education as an indicator for educational attainment in the FFS and the quality of data on educational careers has been thoroughly discussed by Dourleijn et al. (2002).

Table 1:

Dates of the FFS surveys in Central and Eastern Europe

\begin{tabular}{|l|l|c|}
\hline & Date of the survey & $\begin{array}{c}\text { Sample size, women only, } \\
\text { after our cleaning }\end{array}$ \\
\hline Estonia & 1994,1997 & 1709 \\
\hline Latvia & 1995 & 2685 \\
\hline Lithuania & $1994-95$ & 2948 \\
\hline Poland & 1991 & 4203 \\
\hline Czech Republic & 1997 & 1732 \\
\hline Hungary & 1993 (men), & 3538 \\
\hline Slovenia & $1992-93$ (women) & 2781 \\
\hline
\end{tabular}


Table 2:

Descriptive statistics: mean ages at the end of education and at first union and share of women with level 3 education. Source: own elaborations on FFS standard recode files.

\begin{tabular}{|l|c|c|c|c|c|}
\hline \multicolumn{5}{|c|}{ Mean ages } \\
\hline & End of education & Ed. Level 2 & Ed. Level 3 & $1^{\text {st }}$ union & Share of level 3, \% \\
\hline Estonia & 21.3 & 20.4 & 27.2 & 22.0 & 9.1 \\
\hline Latvia & 20.8 & 19.4 & 24.3 & 22.6 & 23.7 \\
\hline Lithuania & 20.8 & 19.2 & 25.0 & 22.1 & 20.4 \\
\hline Poland & 19.2 & 20.2 & 25.9 & 23.0 & 7.1 \\
\hline Czech Republic & 19.6 & 19.7 & 25.3 & 20.8 & 7.1 \\
\hline Hungary & 19.0 & 19.5 & 24.0 & 21.1 & 12.2 \\
\hline Slovenia & 19.8 & 19.3 & 21.4 & 21.4 & 12.5 \\
\hline
\end{tabular}

\subsection{Methods: estimation of a simultaneous hazard model}

We focus on what is known in the literature as the study of parallel and potentially interdependent trajectories in the life courses. There has been a considerable debate in the related literature as to whether one needs to address such trajectories simultaneously (sometimes this is referred to as the "system" approach), or whether it is enough to model the processes separately by adequately conditioning on relevant aspects of the past history of each trajectory (Blossfeld and Rohwer, 2002). In this paper, we follow the approach outlined by Lillard (1993) and we model the two trajectories as potentially affected by correlated unobserved heterogeneity. This heterogeneity may incorporate the effect of ability, or of values and norms that remain unchanged during the part of the life course considered here, i. e., till the end of education and entry into first union, whichever comes later. Values and norms do not remain unchanged during this period of time. The FFS data contain information on values at the time of survey and not at the time when the events took place. This information is insufficient and cannot be used, hence we are not able to access the impact of value orientations.

We therefore model time to the end of education and time to first union using a system of two hazard equations. We formalise a first model:

$$
\begin{aligned}
& \log \mathrm{h}_{\mathrm{U}}(\mathrm{t})=\alpha_{0}^{\prime}+\mathrm{A}_{\mathrm{U}}(\mathrm{t})+\left[\alpha_{1}^{\prime} \mathrm{E}_{\mathrm{L}}(\mathrm{t})+\alpha_{2}^{\prime} \mathrm{E}_{\mathrm{E}}(\mathrm{t})\right]+\alpha_{3}^{\prime} \operatorname{Tr}(\mathrm{t})+\varepsilon \\
& \log \mathrm{h}_{\mathrm{E}}(\mathrm{t})=\beta_{0}^{\prime}+\mathrm{A}_{\mathrm{E}}(\mathrm{t})+\left[\beta_{1}^{\prime} \mathrm{U}(\mathrm{t})\right]+\beta_{2}^{\prime} \operatorname{Tr}(\mathrm{t})+\beta_{3}^{\prime} \mathrm{C}_{\mathrm{T}}(\mathrm{t})+\eta
\end{aligned}
$$

where:

$-\mathrm{h}_{\mathrm{U}}(\mathrm{t})$ and $\mathrm{h}_{\mathrm{E}}(\mathrm{t})$ denote the hazard of the duration till entry into first union (starting at age 15) and the hazard of the duration to end of education (starting at age 10), respectively; 
$-\mathrm{A}_{\mathrm{U}}(\mathrm{t})$ and $\mathrm{A}_{\mathrm{E}}(\mathrm{t})$ denote age, variables represented by a linear spline with knots every two years and starting at age 15 for the union and age 10 for the end of education;

$-\operatorname{Tr}(\mathrm{t})$ is a dummy variable denoting the time at transition for our data (the year 1989);

$-\mathrm{C}_{\mathrm{T}}(\mathrm{t})$ is a variable denoting cohort. We distinguish three cohorts: born before 1960, born between 1960 and 1969, and born after 1969. The first one is the base.

$-\mathrm{E}_{\mathrm{L}}(\mathrm{t}), \mathrm{E}_{\mathrm{E}}(\mathrm{t})$ and $\mathrm{U}(\mathrm{t})$ are time-varying dichotomous variables denoting level of education, end of education, and first-union formation. First unions refer to either marriage or non-marital cohabitation. The level of education is entered in the model using dummy variables that consider the impact of the second level with respect to the first, and of the third level with respect to the second.

$-\varepsilon$ and $\eta$ are normally distributed unobserved characteristics of the individuals with variance equal to one and correlation $\rho$ (which has to be estimated). We fix the variance to 1 because events are not repeatable, and the variance of the unobserved heterogeneity component can only be weakly identified ${ }^{3}$ :

$$
\left(\begin{array}{l}
\varepsilon \\
\eta
\end{array}\right)=N\left(\left(\begin{array}{l}
0 \\
0
\end{array}\right),\left(\begin{array}{ll}
1 & \rho \\
\rho & 1
\end{array}\right)\right)
$$

A second model includes additional control variables for common observed characteristics of women (number of siblings and type of settlement during youth). In addition, in the equation for union formation, it includes an interaction between educational variables and the transition, in order to shed lights on the changing impact of educational careers on the timing of union formation. Models are estimated by full maximum likelihood, using the aML statistical package (Lillard and Panis, 2000).

\section{Results}

Table 3 gives the results of the first model we estimated (coefficients regarding age are omitted, to concentrate our attention on the parameters of main interest). Let us first focus on the equation concerning first union formation. There are some differences in country effects, but the direction is similar across all CEE countries. The effect of educational enrolment is statistically significant for all countries (with parameter estimates ranging from 1.02 in Estonia to 1.56 in Lithuania). In terms of (proportional) hazards, that amounts to a level after the end of education that is from almost 3 to more than 4 times the level before the end of education. When we consider the impact of the level of education, the difference between university and high school level (level 3 vs. level 2) is not statistically significant in most of the countries

3 In other studies, sensitivity analyses have been carried out on this assumption (Baizan et al., 2003; Aassve et al., 2003). 
(with the exception of Latvia and Lithuania). However, the difference between the high school level and lower levels (level 2 vs. level 1) is significant in all countries, with the sole exception of Estonia (where, in fact, the level of education seems to play no role at all).

The delay in the formation of first unions after the fall of Communism is significant in Hungary and Slovenia only, while the Baltic republics (Estonia, Latvia and Lithuania) exhibit on the contrary a quicker transition to first union. To sum up on the transition to first union, the results we obtain show that, even after controlling for endogeneity, both the conclusion and the level of education have a statistically significant impact on the rate of entry into first union in all countries. This impact is as expected from our theoretical framework, both when thinking about sequencing norms (for educational enrolment) and - only partially, which seems justified given the CEE context—human capital theory (for educational level).

Let us now consider the equation concerning the end of education. Entering a union triggers the end of education, as has already been observed for the U.S., with the exception of Hungary (where the impact is surprisingly the opposite), and Slovenia. The competing nature of the two roles is confirmed also when dealing with education as a dependent process. For many countries (exceptions are the Czech Republic and Slovenia), the first years after the fall of communism implied a quicker exit from the educational system. Cohort trends are also very heterogeneous, showing that only in Hungary, Poland and Slovenia the permanence of women in education has increased over cohorts.

Estimated correlation coefficients are negative for the three Baltic republics, close to zero for Poland, Czech and Hungary and positive for Slovenia. The positive correlation may indicate the prevalence of common factors simultaneously affecting both processes in the same direction the timing of both events (i.e., unobserved orientation towards career both prolongs the length of education and delays the formation of a first union), while the negative correlation may indicate the prevalence of other factors (i.e., selection on unobserved ability: entering union earlier means a higher attractiveness on the partnership market and the same may act towards prolonging education). It seems that in the most "Western" of all countries (Slovenia) value orientations play a more important role. However, a negative correlation is consistent with the findings of Lillard et al. (1994) and Upchurch et al. (2001) on U.S. data. Further analyses, however, are needed to investigate on this issue. 
Table 3:

Results of simultaneous hazard models, equation (1).

\begin{tabular}{|c|c|c|c|c|c|c|c|}
\hline & Estonia & Latvia & Lithuania & Poland & Czech R. & Hungary & Slovenia \\
\hline Year of the survey & $1994 / 7$ & 1995 & $1994 / 5$ & 1991 & 1997 & $1992 / 3$ & $1994 / 5$ \\
\hline \multicolumn{8}{|c|}{ Transition to first union } \\
\hline \multicolumn{8}{|c|}{ Educational attainment } \\
\hline Level 2 vs. level 1 & 0.05 & -0.21 & -0.23 & -0.50 & -0.32 & -0.33 & -0.21 \\
\hline Level 3 vs. level 2 & -0.30 & -0.34 & -0.66 & 0.01 & -0.36 & -0.04 & -0.02 \\
\hline \multicolumn{8}{|c|}{ Educational enrolment } \\
\hline No longer enrolled & 1.02 & 1.27 & 1.56 & 1.51 & 1.38 & 1.49 & 1.12 \\
\hline \multicolumn{8}{|l|}{ Period indicator } \\
\hline After the transition & 0.21 & 0.17 & 0.29 & 0.01 & -0.02 & -0.31 & -0.20 \\
\hline \multicolumn{8}{|c|}{ Transition to the end of education } \\
\hline \multicolumn{8}{|l|}{ Union status } \\
\hline In union & 0.36 & 0.31 & 0.58 & 0.16 & 0.45 & -0.23 & -0.07 \\
\hline \multicolumn{8}{|l|}{ Period indicator } \\
\hline After the transition & 0.38 & 0.38 & 0.43 & 0.58 & -0.07 & 0.62 & 0.15 \\
\hline \multicolumn{8}{|l|}{ Cohort indicator } \\
\hline Middle cohort & 0.18 & 0.25 & 0.11 & -0.30 & -0.03 & 0.03 & -0.20 \\
\hline Younger cohort & 0.35 & 0.32 & 0.17 & -0.85 & 0.43 & -0.24 & -0.77 \\
\hline$\rho$ & -0.22 & -0.19 & -0.45 & -0.16 & -0.24 & -0.24 & 0.08 \\
\hline
\end{tabular}

Note: in the models, age dependence is controlled for using piecewise-Gompertz splines. Boldface indicates p-values lower than 0.05 .

In the final model (reported in Table 4) we 1) add further control variables and 2) try to grasp the change after the economic transition of the impact of educational attainment and enrolment on the timing of union formation. For what concerns control variables, results are usually close to general expectations: women coming from larger families (measured with the number of siblings) enter their first union earlier and leave education earlier as well ${ }^{4}$. The urban vs. rural differential is important almost only for the length of education: women who grew up in smaller settlements conclude their education earlier in almost all countries. The inclusion of the new variables does not substantially affect the remaining parameters, including correlation coefficients. If we focus on the impact of educational attainment (Figure 1) and educational enrolment (Figure 2) on the timing of union formation before and after the transition, we find limited results. We need to recall here that FFS are fielded only from 2 to 7 years after the transition, that is the information we get after the transition

4 The size of the family of origin is an example of a factor that could induce a positive correlation between the two duration variables if unobserved. 
is limited and may rarely warrant statistical significance. In general the postponement of the entry into first union for higher educational levels (level 2 vs. level 1 in particular) becomes more important after the transition. Increasing chances for upward mobility after the transition may explain why higher educated women tend to postpone entry into first union even further (on education and first births in East Germany before and after the German unification, see the reasoning of Kreyenfeld, 2000): these opportunities may be less accessible to women with lower education. The impact of educational enrolment is more ambiguous, and in terms of size of the impact the change after the transition is never as important as it is for educational attainment.

Table 4:

Results of simultaneous hazard models, equation (1) and additional variables.

\begin{tabular}{|c|c|c|c|c|c|c|c|}
\hline & Estonia & Latvia & Lithuania & Poland & Czech R. & Hungary & Slovenia \\
\hline \multicolumn{8}{|l|}{ Transition to first union } \\
\hline \multicolumn{8}{|l|}{ Educational level } \\
\hline Level 2 vs. level 1 & 0.01 & -0.13 & -0.21 & -0.44 & -0.21 & -0.35 & -0.11 \\
\hline Level 3 vs. level 2 & -0.32 & -0.30 & -0.61 & 0.07 & -0.24 & 0.15 & 0.04 \\
\hline \multicolumn{8}{|l|}{ Educational enrolment } \\
\hline No longer enrolled & 1.08 & 1.28 & 1.53 & 1.44 & 1.28 & 1.42 & 0.95 \\
\hline \multicolumn{8}{|l|}{ Siblings: } \\
\hline One additional sibling & 0.02 & 0.00 & 0.06 & -0.02 & 0.14 & 0.04 & 0.05 \\
\hline \multicolumn{8}{|c|}{ Size of settlement at age 15 (ref: large): } \\
\hline Small size & -0.06 & -0.08 & -0.37 & 0.13 & 0.17 & 0.10 & 0.09 \\
\hline Medium size & -0.08 & 0.07 & -0.16 & 0.05 & 0.31 & 0.14 & 0.24 \\
\hline \multicolumn{8}{|c|}{ Cohort indicator (ref: Older cohort): } \\
\hline Middle cohort & 0.29 & 0.16 & 0.15 & 0.03 & -0.07 & -0.07 & -0.05 \\
\hline Younger cohort & 1.02 & 0.67 & 0.37 & 0.19 & -0.26 & -0.31 & -0.52 \\
\hline \multicolumn{8}{|l|}{ Period indicator: } \\
\hline After the transition & -0.22 & 0.01 & 0.15 & -0.02 & 0.31 & -0.06 & 0.08 \\
\hline \multicolumn{8}{|c|}{ Interaction of period and educational level } \\
\hline $\begin{array}{l}\text { Level } 2 \text { vs. level } 1 \\
\text { after the transition }\end{array}$ & -0.04 & -0.92 & -0.38 & -0.43 & -0.46 & -0.25 & -0.24 \\
\hline $\begin{array}{l}\text { Level } 3 \text { vs. level } 2 \\
\text { after the transition }\end{array}$ & 0.02 & -0.57 & -0.55 & -0.26 & 0.26 & 0.09 & -0.44 \\
\hline \multicolumn{8}{|c|}{ Interaction of period and educational level } \\
\hline With end of education & -0.35 & 0.17 & 0.34 & -0.11 & -0.10 & -0.40 & 0.30 \\
\hline
\end{tabular}




\begin{tabular}{|c|c|c|c|c|c|c|c|}
\hline & Estonia & Latvia & Lithuania & Poland & Czech R. & Hungary & Slovenia \\
\hline \multicolumn{8}{|c|}{ Transition to the end of education } \\
\hline \multicolumn{8}{|l|}{ Union status: } \\
\hline In union & 0.49 & 0.42 & 0.66 & 0.19 & 0.50 & -0.05 & 0.00 \\
\hline \multicolumn{8}{|l|}{ Work status: } \\
\hline Has ever worked & -0.98 & -0.87 & -0.55 & -0.61 & -1.50 & -1.29 & -0.73 \\
\hline \multicolumn{8}{|l|}{ Siblings: } \\
\hline One additional sibling & 0.10 & 0.15 & 0.11 & 0.15 & 0.21 & 0.29 & 0.22 \\
\hline \multicolumn{8}{|c|}{ Size of settlement at age 15 (ref: large): } \\
\hline Small size & 0.31 & 0.10 & 0.36 & 0.57 & 0.54 & 0.54 & 0.45 \\
\hline Medium size & 0.14 & 0.10 & 0.23 & 0.20 & 0.17 & 0.41 & -0.20 \\
\hline \multicolumn{8}{|c|}{ Cohort indicator (ref: Older cohort): } \\
\hline Middle cohort & 0.20 & 0.29 & 0.19 & -0.30 & -0.03 & 0.04 & -0.15 \\
\hline Younger cohort & 0.33 & 0.38 & 0.26 & -0.85 & 0.51 & -0.17 & -0.64 \\
\hline \multicolumn{8}{|l|}{ Period indicator: } \\
\hline After the transition & 0.38 & 0.38 & 0.46 & 0.64 & -0.07 & 0.57 & 0.15 \\
\hline$\rho$ & -0.24 & -0.21 & -0.45 & -0.10 & -0.11 & -0.12 & 0.19 \\
\hline
\end{tabular}

Note: in the models, age dependence is controlled for using piecewise-Gompertz splines. Boldface indicates p-values lower than 0.05 .

\section{Figure 1:}

Relative risks of first union formation by educational attainment. Point estimates before and after the transition (see table 4).

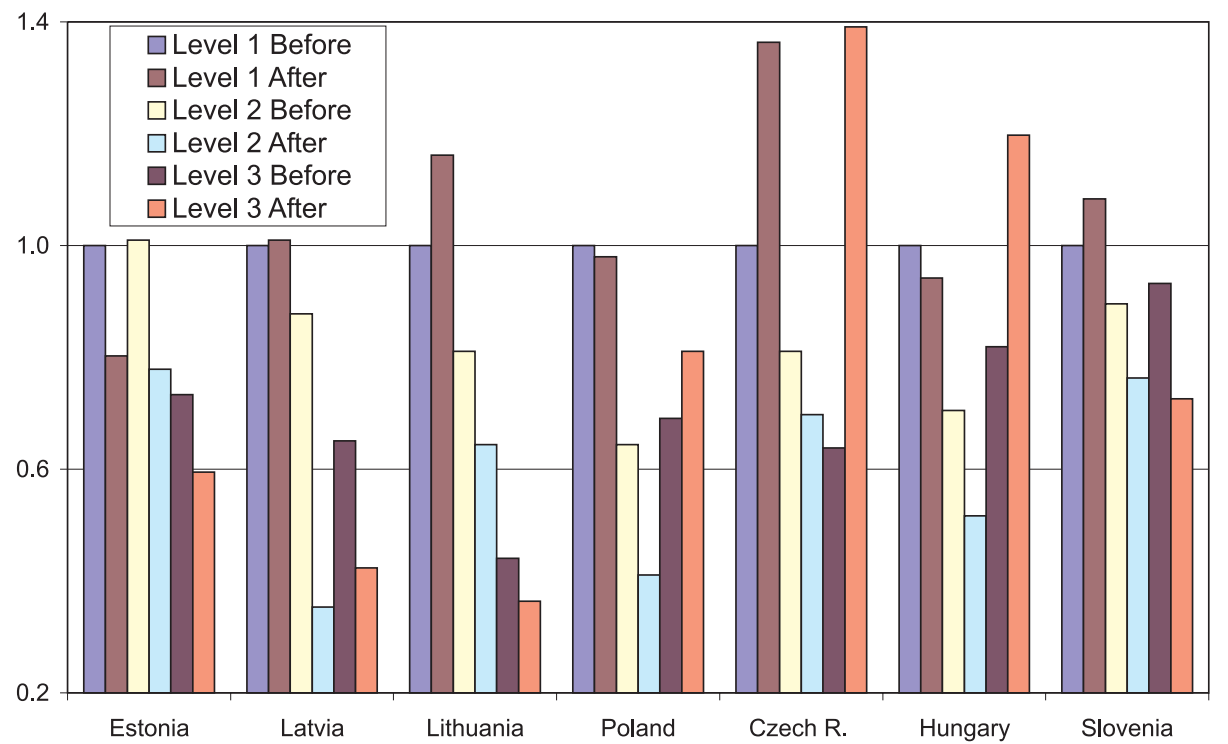


Figure 2:

Relative risks of first union formation by educational enrolment. Point estimates before and after the transition (see table 4).

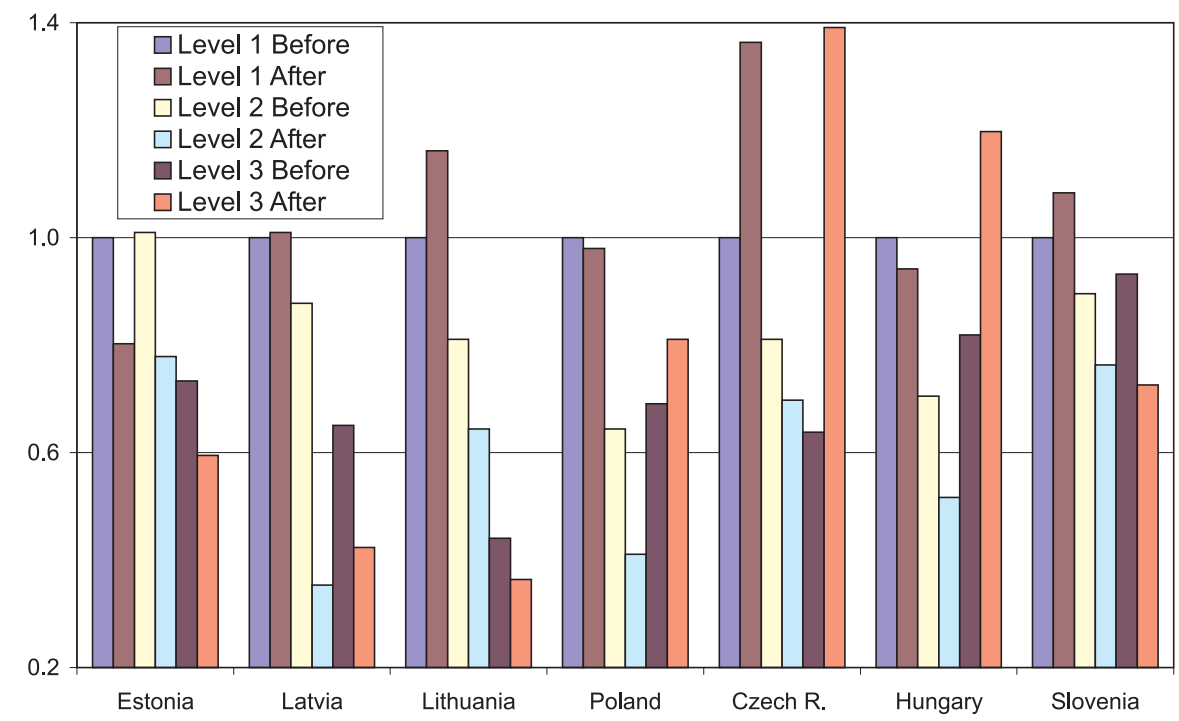

\section{Summary and conclusion}

To sum up, in this paper we studied the interrelationship between educational enrolment and entry into first union (marital or non-marital) for women residing in countries of Central and Eastern Europe, mostly focusing on the pre-transition period. For this purpose, we used a system of two hazard equations that jointly considers the processes of interest. In addition we included the effect of unobserved heterogeneity. Our results indicate that the entry into first union is much more linked to end of education than to the achieved level of education. Nevertheless, after the transition, with increasing opportunities for upward mobility, educational attainment has a greater impact on postponing the formation of a first union.

Let us conclude by indicating some limits of our study. First, given that FFS data were collected shortly after the economic transition of CEE countries, they are not an ideal source to grasp the impact of individual-level differences in orientations, which may start having a more important role after the transition (Lesthaeghe and Surkyn, 2002). In addition, FFS being a retrospective survey, unobserved heterogeneity components necessarily grasp a whole host of factors, for which we have hypothesised some interpretations; the next generation of comparative longitudinal surveys organised within the "Generations and Gender Programme" will help in starting to separate the components now unobserved. Nevertheless, analyses of FFS data constitute a benchmark against which future research on the link between education and family formation in Central and Eastern Europe can be compared. 


\section{Acknowledgements}

Past versions of this paper were presented at the 2002 Annual Meeting of the Population Association of America, Atlanta, Georgia, and at the Workshop on Union Formation in Interdependent Life Courses at the Max Planck Institute for Demographic Research, Rostock. A previous version was published as Billari and Philipov (2003). We wish to thank Ron Lesthaeghe and all participants to the various presentations for comments, and the Advisory Group of the FFS programme of comparative research for its permission, granted under identification number 75 , to use the FFS data on which this study is based. Work on this paper started while the two authors were both affiliated with the Max Planck Institute for Demographic Research (Billari as Head of the Independent Research Group on the Demography of Early Adulthood and Philipov as Senior Research Scientist in the Laboratory for the Analysis of Demographic Data). Of course, views expressed in this paper are attributable to the authors and do not necessarily reflect those of the institutions they belong to nor those of the Max Planck Institute for Demographic Research.

\section{References}

Aassve A., F. C. Billari, F. Michielin, C. Panis. 2003. A Monte Carlo study of (simultaneous) hazard models with flexible baseline and normally distributed error terms, Studi Demografici n. 14, Istituto di Metodi Quantitativi, Università Bocconi, Milano.

Alexander K. L. and T. W. Reilly. 1981. Estimating the Effects of Marriage Timing on Educational Attainment: Some Procedural Issues and Substantive Clarifications, American Journal of Sociology, 87, 143-156.

Astone N. M. and D. M. Upchurch. 1994. Forming a family, leaving school early, and earning a GED-A racial and cohort comparison, Journal of Marriage and the Family, 56: 759-771.

Baizán P., A. Aassve and F. C. Billari. 2003. Cohabitation, marriage and first birth: the interrelationship of family formation events in Spain, European Journal of Population, 19, 147-169.

Barrow M. 1998. Education after communism-the experience of central and eastern European countries, Discussion Paper in Economics 53, University of Sussex, Falmer, Brighton.

Becker G. S. 1991. A Treatise on the Family. Enlarged Edition. Cambridge, MA: Harvard University Press.

Billari, F. C. and D. Philipov. 2003. Mutual relationships between education and women's entry into a first union: the case of Central and Eastern Europe. In: I. E. Kotowska, J. Jóźwiak (Eds.), Population of Central and Eastern Europe. Challenges and Opportunities, Statistical Publishing Establishment, Warsaw: 201-218. 
Blossfeld H.-P. and G. Rohwer. 2002. Techniques of Event History Modeling. Mahwah, NJ: Lawrence Erlbaum Associates.

Blossfeld H.-P. and J. Huinink. 1991. Human capital investments or norms of role transition? How women's schooling and career affect the process of family formation, American Journal of Sociology, 97, 143-168.

Boulier B. L. and M. R. Rosenzweig. 1984. Schooling, Search and Spouse Selection: Testing Economic Theories of Marriage and Household Behavior, Journal of Political Economy, 92, 712-732.

Coppola L. 2003. Education, Employment and Union Formation as Endogenous Processes in Italy and Spain. Unpublished Ph. D. Dissertation, Rome: Department of Demographic Sciences, University of Rome "La Sapienza".

Davis J. N. and L. L. Bumpass. 1976. The Continuation of Education after Marriage among Women in the United States: 1970, Demography, 13, 161-174

Dourleijn E., A. C. Liefbroer and G. C. N. Beets. 2002. Comparing the 1988 International Standard Classification of Education (ISCED) with retrospective information from educational histories, in E. Klijzing, M. Corijn (Eds.), Fertility and partnership in Europe: findings and lessons from comparative research. Volume II. United Nations, New York/Geneva: 157-172.

Friedman D., M. Hechter and S. Kanazawa. 1994. A theory of the value of children, Demography, 31, 375-401.

Goldscheider F. K. and L. J. Waite. 1986. Sex differences in the entry into marriage, American Journal of Sociology, 92, 91-109.

Hakim C. 2003. Preference theory: A new approach to explaining fertility patterns, Population and Development Review, 29, 349-374.

Hajnal J. 1965. European Marriage Patterns on Perspective, in: J. Hajnal, D. V. Glass and D. E. C. Eversley (eds), Population in History: Essays in Historical Demography, 101-143.

Henz U. 1999. The impact of family formation on higher education in Sweden. Stockholm Research Reports in Demography, 135, Stockholm University.

Hoem J. M. 1986. "The impact of education on modern family-union initiation", $E u$ ropean Journal of Population, 2, 113-133.

Hogan D. P. 1978. The variable order of events in the life course, American Sociological Review, 43, 573-86.

Hotz V. J., C. H. Mullin and S. G. Sanders. 1997. Bounding Causal Effects Using Data from a Contaminated Natural Experiment: Analysing the Effect of Teenage Childbearing, Review of Economic Studies, 64: 575-603.

Jansen M. and M. Kalmijn. 2002. Investment in Family Life: the Impact of Value Orientations on Patterns of Consumption, Production and Reproduction in Married and Cohabiting Couples, in R. Lesthaeghe (ed.), Meaning and choice: Value orientations and lifecourse decisions, Den Haag: NIDI CBGS Publications, 129-169. 
Kotowska I. E. and J. Jóźwiak (Eds.). 2003. Population of Central and Eastern Europe. Challenges and Opportunities, Statistical Publishing Establishment, Warsaw.

Kreyenfeld M. 2000. Educational attainment and first births: East Germany before and after the unification, MPIDR Working Paper WP-2000-011, Max Planck Institute for Demographic Research, Rostock.

Lesthaeghe R. and G. Moors. 1995. Living Arrangements and Parenthood: Do Values Matter?, in R. de Moor (ed.), Values in Western Societies, Tilburg: Tilburg University Press.

Lesthaeghe R. and J. Surkyn. 2002. New forms of household formation in Central and Eastern Europe: are they related to newly emerging value orientations, in United Nations Economic Commission for Europe, Economic Survey of Europe, 2002 No. 1, 197-216.

Liefbroer A. C. and M. Corijn. 1999. Who, What, Where, and When? Specifying the Impact of Educational Attainment and Labour Force Participation on Family Formation, European Journal of Population, 15, 45-75.

Lillard L. A. 1993. Simultaneous equations for hazards: Marriage duration and fertility timing, Journal of Econometrics, 56, 189-217.

Lillard L. A. and C. W. A. Panis. 2000. aML Multilevel Multiprocess Statistical Software, Release 1.0, Los Angeles, California: EconWare.

Lillard L. A., C. W. A. Panis and D. M. Upchurch. 1994. Interdependencies over the Life Course: Women's Fertility, Marital, and Educational Experiences. RAND Labor and Population Program, Working Paper Series 94-17, Santa Monica, CA.

Marini M. M. 1984. Age and Sequencing Norms in the Transition to Adulthood, Social Forces, 63, 229-244.

Oppenheimer V. K. 1988. A theory of marriage timing, American Journal of Sociology, 94, 563-591.

Philipov D. and J. Dorbritz. 2003. Demographic consequences of economic transition in countries of central and eastern Europe. Council of Europe Publishing.

Sander W. 1992. Unobserved variables and marital status, Journal of population economics, 5, 217-228.

Singh S. and R. Samara. 1996. Early Marriage Among Women In Developing Countries, International Family Planning Perspectives, 22: 148-157 \& 175.

Sowa K. 1999. Higher Education institutions in the Process of Social Transformation (The Case of Poland), European Education, 31, 63-71.

Thornton A., W. G. Axinn and J. D. Teachman. 1995. The Influence of School Enrollment and Accumulation on Cohabitation and Marriage in Early Adulthood, American Sociological Review, 60: 762-774.

Upchurch D. M. and J. McCarthy. 1990. The timing of a first birth and high school completion, Americal Sociological Review, 55: 224-234. 
Upchurch D. M., L. A. Lillard and C. W. A. Panis. 2001. The impact of nonmarital childbearing on subsequent marital formation and dissolution, in $\mathrm{L}$. Wu and B. Wolfe (eds.), Out of Wedlock: causes and consequences of nonmarital fertility, New York: Russell Sage Foundation, 344-380.

van de Kaa, D. 1987. Europe's second demographic transition. Population Bulletin $42,1$.

Weiss, Y. 1997. Transformation and Dissolution of Families: Why Marry? Who Marries Whom? and What Happens upon Divorce, in Handbook of Population and Family Economics, Volume 1a: 81-120 